\title{
Exceeding the Individual: a Qualitative Examination of a Community-Led Structural Intervention and Its Implications for Sex Workers and Their Families
}

\author{
Samira Ali • Toorjo Ghose • Smarajit Jana • \\ Sambuddha Chaudhuri
}

Published online: 13 May 2014

(C) Springer International Publishing 2014

\begin{abstract}
Introduction While scholarship on community-led structural interventions has focused on contextual modifiers of HIV risk, few studies have examined other aspects of sex workers' lives. The effects of community-led structural interventions are often isolated to individuals' behaviors, such as condom use and number of sexual partners. However, comprehensive approaches toward modifying individuals behavior can also influence aspects of their family life. Evaluating such farreaching effects is essential to better understand the success and sustainability of intervention efforts. In this study, we explore the impact of a sex workers' community-led structural intervention, Durbar Mahila Samanwaya Committee (Durbar), on sex workers and their children. Initiated in 1992, Durbar has been hailed by the World Health Organization as a model community-led structural intervention for sex workers around the world.

Methods In partnership with Durbar, we conducted in-depth, semi-structured qualitative interviews with 35 sex worker mothers. In addition, we engaged in participant observation and documented processes through extensive field notes.
\end{abstract}

\footnotetext{
S. Ali $(\bowtie)$

McSilver Institute for Poverty Policy and Research, New York University, 41 East 11th St., New York, NY 10003-6654, USA

e-mail: sa1112@nyu.edu

T. Ghose

School of Social Policy and Practice, University of Pennsylvania, 3701 Locust Walk, Philadelphia, PA 19104, USA

S. Jana

Durbar Mahila Samanwaya Committee, 12/5 Nilmoni Mitra Street,

Kolkata, West Bengal 700006, India

S. Chaudhuri

School of Social Policy and Practice, University of Pennsylvania, 3815 Walnut Street, Philadelphia, PA 19104, USA
}

Results This study found that the Durbar collective has made various resources available both in the material and symbolic realms that improved the quality of life of sex worker mothers and their children.

Conclusion It is important to evaluate primary intervention outcomes along with other meaningful outcomes that have the potential to secure community buy in and sustain effects over time.

Keywords Sex work - Sex worker mothers - Children of sex workers $\cdot$ Community-led structural intervention $\cdot$ Mothering

In the wake of the HIV/AIDS epidemic, the social sciences have focused unrelentingly on communities that are thought to be high risk due to their sexual practices. Sex workers comprise one such group and have come under heavy scrutiny from researchers and policymakers who try to combat the "HIV problem" (Patton 2002). Such depictions and treatment of sex workers is problematic in that our understanding of sex workers is limited to their "risky" bodies. They have been targeted with a variety of individual interventions that are often driven by assumptions that women engaged in sex work lack agency and that their sexual behaviors should be modified (Campbell 2003; Patton 2002).

While scholarship on community-led structural interventions has focused on contextual modifiers of HIV risk, such as housing, legal environment, and stigma, (Blankenship et al. 2006; Basu et al. 2004; Cornish and Ghosh 2007; Evans and Lambert 2008; Ghose et al. 2008; Jana et al. 1998, 2004; Pardasani 2005), few studies have examined other aspects of sex workers' lives. The Sonagachi Project (SP), run by Durbar Mahila Samanwaya Committee (Durbar), is one such community-led structural intervention. While there is a thorough understanding of Durbar's impact on sex workers' 
health, there is little research about how its programing components influence sex workers' children.

This is surprising given that a significant proportion of sex workers in India are mothers and support families (Sinha and Dasgupta 2009). Sex worker mothers face a host of challenges due to their multiple marginalized positions (Dasgupta 2013; Dodsworth 2012; Sinha and Dasgupta 2009). The intersection of social stigma, poverty, and single motherhood status amplifies the hardships faced by sex workers and their children (Dalla 2004; Dasgupta 2013; Reed et al. 2013; Rolon et al. 2013). Specifically, it is well established that the health and well-being of children living in poverty is intimately connected with their mothers' health status (Reed et al. 2013; Rolon et al. 2013). Moreover, the risk environment of the red-light district strongly influences the sexual risk behavior of both the sex worker mothers and their children (Sinha and Dasgupta 2009; Ghose et al. 2011). Studying either group in isolation gives us a restricted view of the dynamics of health and wellbeing. Thus, this study addresses this crucial gap in our understanding of sex workers' lives by exploring the manner in which Durbar impacts sex workers and their children.

\section{Sex Work in the Context of India}

An estimated one million female sex workers (FSW) live in India (NACO 2013) and over half have children (Sinha and Dasgupta 2009). The first Pan-Indian survey of 3,000 sex workers revealed that most sex workers were between ages 21-35 years and came from poor families, and over half have no formal schooling (Sahni and Shankar 2013). While many women often enter the trade due to economic factors, such as supporting their children and meeting their basic needs, sex work is not their first job in the informal labor market (Devine et al. 2010; Nag 2006; Sahni and Shankar 2013).

About half of FSW out of 3,000, in the Pan-Indian survey, indicated working in other informal labor sectors before engaging in sex work and often voiced experiencing harassment and insufficient income to support their children in their previous jobs (Sahni and Shankar 2013). However, sex work provided them with sufficient income compared to the other opportunities. As such, sex work becomes a viable economic option for women who are otherwise marginalized and do not make more money in other jobs. The relative economic stability derived through sex work also helps better support their families.

Despite the fact that sex work is a viable economic option for some, sex workers live in a complex risk environment that is characterized by the legal, social, physical, and economic hazards. While sex work is legal in India, it is exercised in ambiguous and problematic ways in which soliciting clients, practicing sex work in the public, operating brothels, and sharing income earned from sex work with anyone over the age of 18 are illegal (Sahini et al. 2008; Westmarland and Gangoli 2006). The social environment marginalizes and ultimately inhibits FSW access to various supports (health/mental health access, education, banking) (Basu and Dutta 2010; Cornish 2006; Sinha and Dasgupta 2009). Specifically, scholars have found that discriminatory attitudes and practices by the community, police, service providers, and families lead to increased experiences of violence, harassment, homelessness, and limited access to health care (Basu and Dutta 2010; Cornish 2006; Sinha and Dasgupta 2009; Jayasree 2004).

The physical environment inhabited by sex workers has the potential to serve as harmful or protective spaces. For example, Ghose et al. (2011) conceptualized brothels as protective spaces because they are more regulated and offer more access to supportive services than street-based sex work. While sex work affords women with more economic opportunity than other jobs, their economic environment is often characterized by injustices perpetrated by pimps or local police (Basu and Dutta 2008, 2011).

The combination of these environments leads to increased vulnerability to HIV. In 2009 , FSW accounted for $0.5 \%$ of the female population, however made up $7 \%$ of women who have HIV (NACO 2009). Due to National AIDS Control Organization of India (NACO) prioritization of HIV interventions among the sex worker population, HIV prevalence among FSW has declined from $5.06 \%$ in 2007 to $2.67 \%$ in 2011 (Ministry of Health and Family Welfare 2012; NACO 2012).

\section{Paradigm Shift- the Response to HIV and Sex Work}

The HIV epidemic stimulated research on possible prevention strategies aimed toward a previously ignored community. Public health interventions ranged from sentinel surveillance studies to individual behavioral interventions to communitybased approaches that have involved community members in fighting the epidemic (Campbell and Cornish 2010). Campbell (2003), in her critique of individual level interventions, asserts "the forces shaping sexual behaviour and sexual health are far more complex than individual rational decisions based on simple factual knowledge about health risks, and the availability of medical services" (p. 7). Individual-level HIV intervention informed by social cognitive models focuses only on the proximal factors of behavior (such as attitudes toward the behavior), fails to link the proximal factors with larger, more contextual factors (such as parent and peer relationships, community, culture and functioning of sex trade and practices), and rarely provides guidance on how to change behaviors in the real-world context (Campbell 2003). Involving sex workers in community mobilization interventions is one of the tactics that have proved successful in decreasing HIV transmission rates and enhancing the quality of life of sex workers 
and their families (Campbell and Cornish 2010; Jana et al. 2004; Swendeman et al. 2009).

\section{The Sonagachi Project and Durbar}

The Sonagachi Project (http://www.durbar.org/index.asp) was conceived in Sonagachi in 1992 as a community-based HIV prevention intervention to address the high rates of HIV that was spreading through the community of sex workers. The Sonagachi Project is now a sex worker-led and peer-based HIV intervention that utilizes community empowerment and education to increase condom use and reduce the spread of HIV (Jana et al. 2004). Durbar, which means "unstoppable" in Bengali, now coordinates all Sonagachi Project-related programs, including a sex workers' union and a child of sex worker collective. Differing from individual-level behavior change interventions, Sonagachi Project is community-level structural intervention that aims to change the societal, institutional, and political level perception of sex work and increase access to health care (Blankenship et al. 2006, 2008; Ghose et al. 2008). Durbar has partnered with the Indian Government to implement HIV interventions among sex workers. DMSC has also received funding from the National Institutes of Health, the World Health Organization, and the Bill and Melinda Gates Foundation for various research and capacity building programs. The Sonagachi Project has had substantial success in increasing sex workers' condom use, from $3 \%$ reporting condom use in 1992 to $90 \%$ in 1999 (NACO 2001).

The project now runs a medical clinic, banking cooperative, support groups, and school for children of sex workers. The project has been replicated throughout West Bengal and has been shown to increase condom use at replication sites (Chakrabarty 2004). The Sonagachi Project is now regarded as a model community-based HIV intervention by the World Health Organization (WHO) and for sex worker communities around the world (Gupta et al. 2008; Wallerstein 2006).

\section{Sex Worker Mothers}

While there is little understanding about sex workers' role as mothers, a handful of studies reveal that managing and negotiating motherhood and sex work is often complex and challenging. For many mothers, children are the motivation behind entering and staying in sex work (Dalla 2004; Dodsworth 2012; Sinha and Dasgupta 2009). The structural elements of oppression, unsafe working conditions, and stigma along with the individual stressors of violence and physical and mental health issues create a difficult environment for sex workers who are rearing children (Basu and Dutta 2011; Dalla 2004; Dodsworth 2012; Pardeshi and Bhattacharya 2006; Reed et al.
2013; Sloss and Harper 2004). Similar to single mothers who live in poverty and are often the sole breadwinner of their families, sex workers must navigate the complexities of their work with the demands of childcare (Dalla 2004; Dodsworth 2012; Sinha and Dasgupta 2009). Scholars have found that women with more than one child were also more concerned about their children's health and about their financial circumstances in comparison to those with only one child (Reed et al. 2013). These concerns often prompted sex workers to engage in sex without a condom with clients who offer more money (Reed et al. 2013), indicating that mothers often put themselves in life-threatening situations to provide for their children.

Conversely, the environment of the red-light area has the potential to negatively impact sex workers' children's quality of life. Social and structural issues, such as limited opportunity to attend school, uneven quality of education, stigma, and financial responsibility at young ages, experienced by youth living in poverty have been found to be significantly associated with HIV infection (Underwood et al. 2011; Sinha and Dasgupta 2009).

\section{The Current Study}

Community-led structural interventions have the potential to provide supports that go beyond protecting the health of sex workers. Given the impact on community-led structural interventions on sex workers' lives, it is crucial to examine the manner in which they impact their children as well. This study explores how a sex workers' community-led organization, Durbar, has impacted the family lives of its members. Specifically, we examine how sex workers and their families use material and symbolic resources provided by Durbar.

\section{Methods}

The current paper emerged from a larger study that examined various aspects of sex worker mothers' relationship with their children in the red-light district. In-depth, semi-structured interviews were conducted in 2011 and 2012 with 35 female sex workers. Forty-one female sex workers were approached, and six refused to participate due to scheduling conflicts. In addition to the in-depth interviews, the first author conducted participant observation in 2011 and 2012, utilized field notes and memos, and also attended a variety of meetings and workshops. Content analysis was used to analyze the data (Hsieh and Shannon 2005; Neuendorf 2002).

Convenience sampling was utilized to identify and recruit participants: female sex workers who were parents were identified by Durbar staff and approached by the interviewers. Participants had to be over the age of 18, live in Kolkata, 
India, have a child between the ages of 10-21, speak Bengali or Hindi, and engaged in sex work to be eligible for the study. The interview guide was collaboratively developed through multiple meetings between Durbar stakeholders and the research team. The interview guide covered questions regarding sex worker mothers' experiences with child rearing, such as childcare, access to education and health care, and financial decisions, and their perception of Durbar's impact on their lives. Interviews were conducted in Bengali or Hindi and audio-recorded by a team of trained researchers that included the first author.

Sampling was stopped after theoretical saturation was reached. Theoretical saturation is defined as the stage when new concepts stop emerging from new interviews (Draucker et al. 2007; Glaser and Strauss 1967). Interviews were translated into English, and Computer Aided Qualitative Data Analysis Software Dedoose was used to analyze the data (Dedoose Version 4.5. 2013). Two researchers independently analyzed all 35 transcripts. All of the codes and themes were collaboratively reviewed, and consensus was reached about the most salient themes. Inter-rater reliability was established through a research log that documented the coders' decisions and through continuous discussions about the interpretation of the codes and their placement within each theme (Hall and Stevens 1991; Miles and Huberman 1994). Additionally, rigor was achieved through member checks with various stakeholders at Durbar and peer debriefing with the coauthors (Padgett 2008). IRB clearance was obtained through the University of Pennsylvania and Durbar.

\section{Results}

Participant Demographics

Participants discussed ways in which they utilized Durbar's services. Sex work was the primary source of income for all of the participants. Most (88\%) of the women were brothelbased sex workers, and a few were flying sex workers who travelled daily from the suburbs or village to the red-light district for work. Participants' ages ranged from 25 to 50 years old, with the average age of 33 . Most (91\%) of the participants were involved in sex work for over 10 years. More than half $(66 \%)$ of the women had two or more children. Their children's ages ranged from 10 to 21 years old, with a mean age of 14, and about half were female. Fifty-four percent of the children lived with their mothers, $24 \%$ lived with extended family in the village, and $22 \%$ lived in boarding schools. All of the participants were the primary financial support for their families, and many (over $70 \%$ ) also noted financially supporting their extended families, such as siblings or parents. Most ( $86 \%)$ of the women were single parents.

\section{Material Resources}

Many of our participants underscored the importance of sex work in supporting their family. Durbar provided sex workers with tangible material resources that ultimately improved the health and well-being of their family.

\section{Health Care}

Durbar operates several primary care and sexually transmitted infection (STI) clinics across the red-light areas in West Bengal. Although started with the objective of STI screening and treatment, the clinics have evolved into primary care centers serving sex workers and their families. One participant notes:

We all come to the clinics. My elder son had a fever and the doctor here gave him medicine. Going to the hospital is so much trouble and private doctors charge so much money. We use the clinic for all of our health problems, not just AIDS problems. If I was living away from here, I would have to go to the government hospital which would take me a whole day. That's what we had to do before...

Although India has a nationalized health care system along with a private health care industry, the system is overburdened and often difficult to access. Having health clinics in the red-light districts has encouraged people in the neighborhood to seek health care in a timely fashion. Most of these visits also serve as teaching moments around preventive care issues such as hazardous substance use, smoking, and personal hygiene.

The respect and sensitivity with which the Durbar clinicians engage clients differentiate them from the staff in other clinics and hospital. One participant notes:

This work is not recognized. When I go to government hospital I have to lie about my work and if they somehow come to know they look at you strangely and are also odd to my daughter. Here everyone knows and we can be free with the doctor.

The neighborhood clinics in the red-light district overcome the two common barriers confronting marginalized sex workers: difficulty accessing health care sites and insensitive providers who are biased against them.

Going to the clinic for some women has become part of the daily routine since the clinic space often doubles up as a drop-in center and is contiguous to the Durbar offices. For example, the collaborator of this study, who herself is a daughter of a sex worker, showed up looking ill to one of the research meetings. When one of the team members asked her what was wrong, she informed the group that 
she was suffering from a boil on her flank. Concerned about her state, some team members asked her to take the day off. She replied:

Don't worry. When we go to that field (red-light area) I will get a quick check up with the doctor at the clinic. Why waste a day going to the hospital when I can do my work and also get a check-up at the same time.

\section{Education}

Clinic spaces are also used for children's after-school programs. These programs are based on a peer-mentoring model, where older children help their younger counterparts with homework and school projects. These spaces also operate as play spaces where children get together for afternoon recreations. In the crammed red-light neighborhoods, having access to safe spaces where their children can meet, work, and play with their peers solves the dilemma of childcare for poor, working mothers. Many of the women work out of their homes, and prior to the creation of these multipurpose spaces, children would roam around the streets for long hours in the afternoon and evening. One participant highlights her thoughts about the space:

When I go to my sisters' neighborhood I see so many children in the streets all the time. Here our children have this space. I can do my work in the evening and I know someone is watching over them. Our children do not run wild anymore.

In addition to after-school activities, some red-light areas run night schools for children who do not attend regular schools. Many children face heightened stigma when transitioning from primary to middle school either through bullying or unsympathetic attitude from authority figures, and as a result, there is a high dropout rate in this age group. These night schools provide children who have dropped out from school an opportunity to complete their education. One mother discusses the impact of the night school on her child:

My older son stopped going to school after 7 th grade. My younger son also dropped out when he was 12 years old. But he has been going to the night school for the last 2 years. He wants to get his high school diploma. That was not possible in the public school.

While high school dropout rates are high among children from low-income families, there are few opportunities for them to complete their education outside the public school system. Durbar night schools offer a unique opportunity to the residents of the red-light area to come back to school to complete their education. To further address this issue and the housing challenges confronting sex workers with children, Durbar has also opened two residential schools in the suburbs of Kolkata.

\section{Civic Engagement and Extracurricular Activities}

Apart from catering to the educational needs for the children, Durbar has actively engaged the children of sex workers in civic engagement and extracurricular activities. Reflecting the values of Durbar, Amra Padatik ("We, the foot soldiers") spearheads advocacy against the discrimination of sex workers' children in schools and other public institutions. They organize workshops and activities that teach strategies to advocate against such discrimination in work and educational spaces. Explaining how these workshops have helped her daughter, one mother notes:

My daughter goes to all of the trainings (workshops) at Amra Padatik. She loves it there. The other day she tells me 'mom, you know they told us how to stand up to someone who abuses you in school, now I know how to defeat them'. I felt so happy and proud, it has been so difficult to protect my children against society's abuse as they think it is bad what we do. I am happy that she learns the lessons to protect herself from the bad elements.

Komal Ghandar, Durbar's cultural wing, and the soccer league are two other important avenues for the sex workers' children to get involved in extracurricular activities. Specifically, the platform provided by Komal Ghandar offers youth a unique opportunity to showcase their talents in the performing arts, while simultaneously advocating for social change around sex workers' issues. The following excerpt from their website succinctly summarizes Komal Ghandar's multilayered agenda.

All Durbar cultural activities are used pragmatically as tools for HIV prevention work - raising awareness and challenging stigma, and also used as a strategic front to sharpen Durbar's movement in highlighting sex workers' rights, bringing sex workers' demands into the public arena, and challenging dominant stereotypic representations of sex work and sex workers. Komol Gandhar gives sex workers and their children an opportunity to claim the rights to joy full life and a space to express through cultural performances. This medium has helped them to express their creativity, help them to pacify some of the brutalized experiences of being sex workers or their children, at the same time by unleashing a huge opportunity to express their potential imaginary and creativity. It gives sex workers a 'voice' to negotiate with mainstream society. 
One of the mothers expresses her delight with the way her daughter has become involved in dancing:

My daughter loves to dance. There is no opportunity for her to learn dancing at the school but after she joined Komal Gandhar she has participated in dance workshops and has performed at international conferences.

Soccer, or football as it is known in India, is a much loved and widely followed sport. It is a common sight to see children playing the sport in street corners and neighborhood parks. Responding to the enthusiasm around this sport, Durbar organized a soccer league for children in the red-light district under the tutelage of a retired professional soccer player. Echoing the agenda of greater visibility of the marginalized in public spaces, the soccer team has made it to the local and national news not only for its many victories but also for advocating for their mothers' rights to work as sex workers.

These various initiatives provide an opportunity for some children in the red-light neighborhood to gather and socialize with their peers under the mentorship of older children or young adults. The mothers, who often entertain clients in their living quarters, struggle to identify alternative spaces for their children to stay in while they are engaged in work. In one of the red-light districts served by a Durbar office, which did not have room for a children's community center, many mothers noted the lack of a safe space for their children. They compared their situation unfavorably to other Durbar offices and clinics that had such a provision. Many noted the stronger presence of the children's collective as a result of such available centers, thus underscoring the importance of safe spaces for their children.

\section{USHA}

Emerging out of the Sonagachi Project, USHA is a cooperative bank that is based on the microfinance model and provides microloans at less than market interest rates. Initiated in 1995, at a time when most sex workers were denied the right to own properties, bank accounts, and legal identifications, USHA stemmed from the impetus that sex workers should have their own financial institution. What began as a dozen women pooling their resources to generate capital soon turned into Asia's first and largest cooperative entirely owned and managed by sex workers. By providing low-interest loans and savings accounts, USHA has played a significant role in sex workers' lives. Moreover, allowing sex workers to sit on the board to make important decisions about investments and portfolio management has increased the confidence and negotiating power of some of the participating women. This sense of empowerment and access to financial planning has increased the capacity of many mothers to provide for their children.
One participant shared her feelings about USHA:

Whatever I have earned before, I spent it all. I was worried about how my son will manage if I were to die tomorrow. Now he can have the money in my USHA account. I have been putting away some money every month for the past five years. I also repaid the loan that I had taken out for my daughters' wedding.

USHA offers sex workers the tools to better manage their finances and, as observed by some of our participants, to plan toward financial security of their children.

\section{Peer Education-Substantive Context}

One of the key features of the Sonagachi Project is the peer education HIV intervention (Jana et al. 2004). The Durbar collective trains sex workers to educate peers about safer sexual practices and sex workers' rights and encourage health care checkups at the project's clinics. Through intensive workshops, Durbar has trained over 400 peer educators on educating sex workers about HIV and STI, condom use negotiation tactics with clients, as well as other sexual health-related information (Jana et al. 2004; personal communication with Dr. Smarajit Jana). Beyond the educational aspect, the role of peer educators, however, is one of building a cohesive community among sex workers. Specifically, the peer education program can be best described by the following:

Our initial peer education programme was designed not only for outreach activities but also for attainment of self-reliance, confidence and dignity and to transfer that image to influence other members of the community which actually facilitated the creation of a base whereby the sex workers could network among themselves and function as a group for collective bargaining....initially they started as health educators but they gradually got transformed and they fit themselves into the bigger canvas of society to act as a community leader, community mobiliser and as an agent of social change (AIIHPH 1997).

Engagement in peer education gives mothers educational tools, such as pamphlets and flip charts, that are often used to initiate conversations about sensitive topics with their children. By using a Sonagachi Project pamphlet, one mother was able to strike a conversation with her son about sex:

We do peer education around the brothel areas. We use a pamphlet to educate the sex workers. This pamphlet always stays in my purse. One day, my son asked me, mom what is this? So I said, read it. I told him a little and then also told him what happens between a 
girl and boy and sex. So, I said the place where a girl and boy have sex, that place can have gonorrhea. It was easier to have the conversation with him because I had the pamphlet.

\section{Symbolic Resources}

\section{Peer Education-Empowering Process}

Peer education also functioned as a component of Durbar that enhanced participants' self-efficacy and sense of empowerment. Many women view the lack of education as an inadequacy in their roles as parents. Peer education training instills a sense of confidence around their ability to effectively communicate and influence people's opinions. One participant discusses her growth as a peer educator:

This is what I do with other people. I had never gone to school...do not know how to read. Then when I joined as peer educator, I was not sure if I could do it. But as I attended more training, I saw that people listened to me. I can say something and they will understand, nod their heads and say 'you are right didi (sister)'. That was so good, now I talk and people listen. People in my field of work and also people at home.

This newfound confidence often translates into more comfortable exchanges with their children around sensitive topics, such as sexual health. Another participant describes a recent interaction with her son:

I felt very good when he (my son) asked me about it (HIV). I don't know how to read or write, but my children do. Because they know how to read and write, they want to know more information. Even though I don't know how to read and write, I still know about HIV because of Durbar. It was so good to discuss this with him.

Broaching sexual health, though initially awkward, signals openness for other difficult and sensitive conversations with children. Many mothers believed that this resulted in a friendlier relationship with their children.

\section{Participating in Civic Engagement and Mobilizing Sex Workers' Rights}

Durbar has created multiple opportunities for sex workers to sit on committees, play important roles in decision making, and to publicly engage with sex workers' rights initiatives. Activities such as rallies, protest demonstrations, and street plays represent ways in which Durbar has mobilized sex workers to lay claim to public space. Reflecting on Durbar and her position as a sex worker, one participant notes:

Sex work is good work. The government has not yet given us official recognition, so we cannot openly identify as sex workers. But in certain forums like government meeting or workshops we can come out as sex workers. We love and respect our work. We think it is honest work. I've only started to feel like this after joining Durbar and becoming a peer educator... through their trainings. Earlier (before Durbar) I was not sure about sex work and I did not know about these things (sex work, protection, HIV) much. We had to be secretive and were often forced into sex work. Now sex work is entirely up to us, whether or not we want to or not want to do it (sex work), it is entirely my personal matter. We have gained the courage to speak our minds.

While such actions target greater public awareness about sex workers' rights, they have transformative potential in forming attitudes about discussions regarding sensitive topics with children. Describing how that it was her duty to disclose to her son about the profession, one participant noted:

I am a peer educator. I talk to others about taking pride in their work and protecting themselves from HIV. I walk in the rallies. How can I not talk to my son about this work? When he knows all about it I think he will respect me more.

\section{Anti-trafficking Initiatives}

Seeking to validate their experience as legitimate laborers, Durbar has mobilized sex workers to engage with antitrafficking laws, such as India's Immoral Trafficking Prevention Act (ITPA). According to the ITPA, sex work is legal; however, soliciting clients, practicing sex work in the public, operating brothels, and sharing income earned from sex work with anyone over the age of 18 are illegal (Sahini et al. 2008; Westmarland and Gangoli 2006). Many sex workers are criminalized for their work because they often fall under one of the aforementioned categories. This problematic homogenous category labels all sex workers as victims of trafficking, not taking their choice to work as a sex worker into account. Furthermore, the terminology used in the ITPA is ambiguous, leading to different interpretations and misuse of the law by authorities. In addition, the ITPA states that it is illegal for sex workers to share their income with anyone above the age of 18. This component of the law is extremely problematic because many children who are over the age of 18 continue to be supported by their mothers' income.

Durbar has mobilized its members to actively protest against the ITPA. One mother discussed her previous worries 
about getting picked up by the police and her own engagement with Durbar.

Before Durbar, in my other neighborhood, I was always afraid of the police harassing me. This is before Durbar came about... I was always worried about what my children would do if the police caught me. But, since Durbar has come about, things have changed and I feel much safer now and I don't have to worry about my children. Durbar works with all of the officials here. I have participated in many rallies about making sex work legitimate.. it should be so that other sex workers don't have to worry.. Under the law right now I cannot share my income with my eldest child. That is not right.

Engagement in Durbar's advocacy initiatives allows some mothers to assert their identity as parents, as well as sex workers, and work toward securing their rights as mothers.

\section{Discussion}

\section{Summary of Results}

While scholars have examined Durbar's effects on individual behavior and how it has grown into a multifaceted, community-based service and advocacy organization (Ghose et al. 2008; Jana et al. 2004; Swendeman et al. 2009), no study has examined the multilayered effect it has on the role of sex workers as mothers. This study found that the Durbar collective has made various resources available both in the material and symbolic realms that mothers used to improve the quality of their life with their children. Given that the Sonagachi Project started as a HIV prevention initiative, the health care service provided by the community clinics constitutes an important focus of the program. The ease of access and the de-stigmatized space of the clinics encourage not only the sex workers but also their families to promptly seek everyday health care. Serving as the first point of contact, the primary care clinics also link sex workers and their families to a host of other services.

The other direct contribution of the Durbar collective to the welfare of the children of sex workers is through its various initiatives around children's education. After school drop-in centers, night schools, and residential boarding schools developed by Durbar over the past 15 years provide unique opportunities for supporting education in children who otherwise face the complex challenges of a hostile and discriminating public school environment. Complementing the education services, Durbar provides support for cultural and other extracurricular activities for the children of sex workers. The children's collective, Amra Padatik, serves as a community space which structures the social lives of children in red-light area.
The cultural group, Komal Ghandar, and the soccer league represent two additional opportunities for children to align with the greater advocacy agenda of Durbar while they engage with their extracurricular interests. USHA, the cooperative bank that has evolved in tandem with Durbar, provides mothers with tools for planning the financial future of their children.

Durbar has mobilized around the groundbreaking concept that sex work is a legitimate choice for women engaged in wage labor. Since its inception, Durbar has (re)framed sex work as legitimate work by organizing and mobilizing sex workers to engage in political and community advocacy, raising consciousness within the FSW community and various stakeholders, and incorporating a human rights-based model of advocacy (Ghose et al. 2008; Swendeman et al. 2009). Furthermore, Durbar encourages political advocacy participation through sex workers' rights rallies, national and international sex work conferences, and leadership roles that provide opportunities to engage and negotiate with local and national politicians and institutions that have a long history of being oppressive agents. Ghose et al. (2008) suggest that framing sex work as "legitimate work," as Durbar has done, aligns sex work with other labor rights movements and destigmatizes sex work through identifying oppressive agents at community and structural levels.

These sensitizing processes have not only helped sex workers reconfigure themselves as legitimate workers but also had far-reaching effects on their personal family lives. This very process improves sex workers' self esteem and confidence and helps them to exert their human agency. The sense of empowerment derived though the sex workers' right discourse mobilized by Durbar has helped some sex workers to reconfigure themselves within the family as legitimate earning members and as confident mothers. Participating in peer education initiatives helps sex workers overcome barriers such as illiteracy and lack of formal education. Obtaining peer education training about communicating with people helps sex workers initiate conversations about sensitive topics with their children. Civic engagement through participating in rallies and protest demonstrations consolidates a newfound selfconfidence, and for some, it positively impacts the interaction with their children.

Practice and Research Implications

While existing scholarship has identified the success of community-led structural interventions among sex workers, this paper illustrates its effect not only on the sex workers but also their families. While evaluating interventions, focusing too narrowly on primary outcomes, such as condom use, number of sex partners, and intimate partner violence, occludes the possibility of detecting other meaningful effects. 
Such post hoc analyses of structural interventions provide valuable feedback and are instructive for replication efforts.

Engaging families in support services has been documented to be challenging task due to client-level logistical issues and provider-specific constraints (Gopalan et al. 2010; Mckay and Bannon 2004). However, interventions should systematically include family-centered services that have the potential to secure buy-in from individuals as well as their families. This study illustrates the way in which such a holistic approach toward support services can be achieved in resourcepoor settings. For example, we found that Durbar's clinic space was used in different times of the day for multiple purposes, such as after-school programs and meeting space for peer educators. Such an expedient use of space meets multiple needs.

Since individuals exist in a web of complicated relationships and environments, it is essential to design interventions with such complexity in mind. As mentioned before, Durbar has emerged from its inception as a HIV prevention initiative to its present state of a community-based advocacy organization that caters to the multiple dimensions of women's lives. The iterative process of inquiring into the evolving needs of the collectives' members has prompted Durbar to constitute new services, explore underserved issues, and modify existing practices. Many participants opined that Durbar has become increasingly relevant in their lives as it has grown to fulfill a spectrum of needs. Social welfare interventions when grounded in communities and cognizant of the complex processes of the communities that they seek to target have the ability to become vehicles of social change, as shown by the constellation of programs developed to support sex workers (Jana et al. 2004). Moreover, global and local community-based research efforts should be rooted in a deep contextual understanding of the existing problems and needs, along with the available resources. Such an understanding is only possible through a constant iterative research process that allows for an organic exchange of knowledge among the collaborators (Parker et al. 2014).

\section{Policy Implications}

Criminalizing sex work not only delegitimizes the labor of certain women but also fails to recognize the way it perpetuates poverty and violence on the dependent children of sex workers (Rekart 2005). The criminalization of sex work has been found to increase police harassment, HIV/AIDS risk, violence, and stigma and discrimination (Ahmad 2001; Blankenship and Koester 2002; Open Society 2010; Pauw and Brener 2003; Shannon et al. 2008; Shannon and Csete 2010; UNAIDS 2002; WHO 2001). Such an environment exposes children to witness police brutality, often leaving children vulnerable and unaccounted for once the mother is incarcerated. Additionally, the criminalization of sex work perpetuates stigma that restricts access to health care for both sex workers and their children. Given that the criminalization of sex work also leads to unsafe working conditions for sex workers and heightened risk for HIV, children's lives get impacted if mothers are infected with the disease and not able to care for their children. Recent research examining the impact on decriminalization on the lives of sex workers has found that it leads to reduction in police brutality and violence, increases access to health care, promotes occupational safety, and reduces HIV risk (Abel et al. 2009; Open Society 2010).

This paper exclusively focuses on how the Durbar collective fulfills the needs of sex worker mothers in the context of their family lives. Future studies should conduct an in-depth analysis of how mothers who are sex workers negotiate motherhood in the red-light district. Recovering the stories of populations that have been systematically excluded from the narrative of development is the first step toward developing relevant and sustainable interventions.

\section{References}

A.I.I.H.P.H. (1997). Five year's stint at Sonagachi: a dream, a pledge, a fulfillment. Calcutta: Department of Epidemiology, All India Institute of Hygiene and Public Health.

Abel, G., Fitzgerald, L., \& Brunton, C. (2009). The impact of decriminalisation on the number of sex workers in New Zealand. Journal of Social Policy, 38(3), 515-531.

Ahmad, K. (2001). Call for decriminalisation of prostitution in Asia. Lancet, 358, 643.

Basu, A., \& Dutta, M. (2008). Participatory change in a campaign led by sex workers: connecting resistance to action-oriented agency. Qualitative Health Research, 18, 106-19.

Basu, A., \& Dutta, M. (2010). Born into brothels: neocolonial moves and unheard voices. Feminist Media Studies, 10, 101-05.

Basu, A., \& Dutta, M. (2011). We are mothers first: localocetnric articulation of sex worker identity as a key in HIV/AIDS communication. Women and Health, 51, 106-123.

Basu, I., Jana, S., Rotheram-Borus, M. J., Swendeman, D., Lee, S. J., Newman, P., \& Weiss, R. (2004). HIV prevention among sex workers in India. Journal of Acquired Immune Deficiency Syndromes, 36(3), 845-52.

Blankenship, K., \& Koester, S. (2002). Criminal law, policing policy, and HIV risk in female street sex workers and injection drug users. Journal of Law Medical Ethics, 30, 548-559.

Blankenship, K., Friedman, S., Dworkin, S., \& Mantell, J. (2006). Structural interventions: concepts, challenges and opportunities for research. Journal of Urban Health, 83, 59-72.

Blankenship, K., West, B. S., Kershaw, T. S., \& Biradavolu, M. R. (2008). Power, community mobilization, and condom use practices among female sex workers in Andhra Pradesh, India. AIDS, 22(5), S109S116.

Campbell, C. (2003). Letting them die: why HIV/AIDS intervention programmes fail. Bloomington: Indiana University Press.

Campbell, C., \& Cornish, F. (2010). Towards a "fourth generation" of approaches to HIV/AIDS management: creating contexts for effective community mobilisation. AIDS Care, 22(Suppl 2), 1569-79.

Chakrabarty, I. (2004). Influence of rights-based approach in achieving success in HIV program and in improving the life of sex workers. Kolkata: Durbar Mahila Samanwaya Committee Publication. 
Cornish, F. (2006). Challenging the stigma of sex work in India: material context and symbolic change. Journal of Community and Applied Social Psychology, 471, 462-471.

Cornish, F., \& Ghosh, R. (2007). The necessary contradictions of 'community-led' health promotion: a case study of HIV prevention in an Indian red light district. Social Science and Medicine, 64(2), 496-507.

Dalla, R. (2004). "I fell off [the mothering] track": barriers to "effective mothering" among prostituted women. Family Relations, 53(2), 190-200.

Dasgupta, S. (2013). Poverty as a contextual factor affecting sexual health behavior among female sex workers in India. Qualitative Health Research, 23(6), 825-833.

Devine, A., Bowen, K., Dzuvichu, B., Rungsung, R., \& Kermode, M. (2010). Pathways to sex-work in Nagaland, India: implications for HIV prevention and community mobilisation. AIDS Care, 22(2), 228-237.

Dodsworth, J. (2012). Sex worker and mother: managing dual and threatened identities. Child and Family Social Work, 19(1), 1-10.

Draucker, C. B., Martsolf, D. S., Ross, R., \& Rusk, T. B. (2007). Theoretical sampling and category development in grounded theory. Qualitative Health Research, 17, 1137-1148.

Evans, C., \& Lambert, H. (2008). The limits of behaviour change theory: condom use and contexts of HIV risk in the Kolkata sex industry. Culture, Health and Sexuality, 10(1), 27-41.

Ghose, T., Swendeman, D., George, S., \& Chowdhury, D. (2008). Mobilizing collective identity to reduce HIV risk among sex workers in Sonagachi, India: the boundaries, consciousness, negotiation (BCN) framework. Social Science and Medicine, 67, 311-320.

Ghose, T., Swendeman, D. T., \& George, S. M. (2011). The role of brothels in reducing HIV risk in Sonagachi, India. Qualitative Health Research, 21, 587-600.

Glaser, B. G., \& Strauss, A. L. (1967). The discovery of grounded theory: strategies for qualitative research. New York: Aldine.

Gopalan, G., Goldstein, L., Klingenstein, K., Sicher, C., \& McKay, M. (2010). Engaging vulnerable youth and their families. Journal of Canadian Child Psychiatry, 19, 182-196.

Gupta, G., Parkhurst, J., Ogden, J., Aggleton, P., \& Mahal, A. (2008). Structural approaches to HIV prevention. Lancet, 37, 764-775.

Hall, J. M., \& Stevens, P. E. (1991). Rigor in feminist research. Advances in Nursing Science, 13(3), 16-29.

Hsieh, H. F., \& Shannon, S. E. (2005). Three approaches to qualitative content analysis. Qualitative Health Research, 15(9), 1277-1288.

Jana, S., Bandyopadhyay, N., Mukherjee, S., Dutta, N., Basu, I., \& Saha, A. (1998). STD/HIV intervention with sex workers in West Bengal, India. AIDS, 12(Suppl. B), S101-S108.

Jana, S., Basu, I., Rotheram-borus, M. J., \& Newman, P. A. (2004). The Sonagachi Project: a sustainable community intervention program. AIDS Education and Prevention, 16, 405-414.

Jayasree, A. K. (2004). Searching for justice for body and self in a coercive environment: sex work in Kerala, India. Reproductive Health Matters, 12(23), 58-67.

McKay, M., \& Bannon, W. (2004). Evidence update: engaging families in child mental health services. Child \& Adolescent Psychiatric Clinics of North America, 40, 1-17.

Miles, M. B., \& Huberman, A. M. (1994). Qualitative data analysis: an expanded sourcebook (2nd ed.). Thousand Oaks: Sage.

Ministry of Health and Family Welfare, Government of India (2012). HIV estimations report. Press Information Bureau.Retrieved from http://pib.nic.in/newsite/PrintRelease. aspx?relid=89785.

NACO (National AIDS Control Organisation) (2012) HIV sentinel surveillance. 2010-11. A technical brief.

NACO (National AIDS Control Organisation) (2013). Annual report (2012-2013). Retrieved from http://www.naco.gov.in/upload/ Publication/Annual\%20Report/Annual\%20report\%202012-13_ English.pdf.
Nag, M. (2006). Sex worker of India. New Delhi: Allied Publishers Private.

National AIDS Control Organization (NACO) (2001). Combating HIV/ AIDS in India, 2001. Retrieved from http://naco.nic.in/vsnaco/ indianscene/country.htm.

National AIDS Control Organization (NACO) (2009). Department of AIDS control annual report. Retrieved from http://www. nacoonline.org/NACO.

Neuendorf, K. A. (2002). The content analysis guidebook. Thousand Oaks: Sage.

Open Society (2010). 10 reasons to decriminalize sex work: a reference brief. Retrieved from http://www.soros.org/sites/default/files/ decriminalize-sex-work-20120713.pdf.

Padgett, D. (2008). Qualitative methods in social work research. New York: Sage.

Pardasani, M. (2005). A context-specific community practice model of women's empowerment: lessons learned in rural India. Journal of Community Practice, 13(1), 87-103.

Pardeshi, G., \& Bhattacharya, S. (2006). Child rearing practices amongst brothel based commercial sex workers. Indian Journal of Medical Sciences, 60, 288-295.

Parker, G., Ali, S., Ringell, K., \& McKay, M. (2014). Bi-directional exchange: the cornerstone of globally focused social work. Global Social Welfare: Research Policy and Practice, 1(1), 1-8.

Patton, C. (2002). Globalizing aids. Minneapolis: University of Minnesota Press.

Pauw, I., \& Brener, L. (2003). "You are just whores - you can't be raped": barriers to safer sex practices among women street sex workers in Cape Town. Culture Health Sexuality, 5, 465-481.

Reed, E., Silverman, J. G., Stein, B., Erausquin, J. T., Biradavolu, M., Rosenberg, A., \& Blankenship, K. M. (2013). Motherhood and HIV risk among female sex workers in Andhra Pradesh, India: the need to consider women's life contexts. AIDS and Behavior, 17(2), 543-50.

Rekart, M. L. (2005). Sex-work harm reduction. Lancet, 366, 2123-2134.

Rolon, M. L., Syvertsen, J. L., Robertson, A. M., Rangel, M. G., Martinez, G., Ulibarri, M. D., ... \& Strathdee, S. A. (2013). The influence of having children on HIV-related risk behaviors of female sex workers and their intimate male partners in two Mexico-US border cities.Journal of tropical pediatrics, 59(3), 214-219.

Sahini, R., Shankar, V. K., \& Apete, H. (Eds.). (2008). Prostitution and beyond: an analysis of sex work in India. New Delhi: Sage.

Sahni, R., \& Shankar, V.K. (2013). Sex work and its linkages with informal labour markets in India: findings from the first Pan-India survey of female sex workers, IDS Working Paper 416, Brighton: IDS.

Shannon, K., \& Csete, J. (2010). Violence, condom negotiation and HIV/ STI risk among sex workers. Journal of the American Medical Association, 304(5), 573-74.

Shannon, K., Rusch, M., Shoveller, J., Alexson, D., Gibson, K., \& Tyndall, M. W. (2008). Mapping violence and policing as an environmental-structural barrier to health service and syringe availability among substance-using women in street-level sex work. The International Journal on Drug Policy, 19, 140-7.

Sinha, I., \& Dasgupta, S. H. (2009). Mothers for sale in Kolkata's sex trade. Calcutta: Dasgupta Alliance.

Sloss, C. M., \& Harper, G. W. (2004). When street sex workers are mothers. Archives of Sexual Behavior, 33(4), 329-41.

Swendeman, D., Basu, I., Das, S., Jana, S., \& Rotheram-Borus, M. J. (2009). Empowering sex workers in India to reduce vulnerability to HIV and sexually transmitted diseases. Social Science and Medicine, 69(8), 1157-66.

UNAIDS (2002). Sex work and HIV/AIDS. Geneva: Joint United Nations Programme on HIV/AIDS. Retrieved from http://www. data.unaids.org/publications/IRC-pub02/jc705-sexwork-tu en.pdf.

Underwood, C., Skinner, J., Osman, N., \& Schwandt, H. (2011). Structural determinants of adolescent girls' vulnerability to HIV: 
views from community members in Botswana, Malawi, and Mozambique. Social Science and Medicine, 73(2), 343-50.

Wallerstein, N. (2006). What is the effectiveness of empowerment to improve health? Copenhagen: World Health Organization Regional Office for Europe. Retrieved from http://www.euro.who. int/Document/E88086.pdf.
Westmarland, N., \& Gangoli, G. (2006). Introduction: approaches to prostitution. In G. Gangoli \& N. Westnarland (Eds.), International approaches to prostitution, law and policy in Europe and Asia (pp. 1-17). UK: The Policy Press.

World Health Organization (WHO). (2001). Sex work in Asia. Geneva: World Health Organization. 